Correspondence

\title{
Is elite sport activity associated with specific supranormal left ventricular contractility? (Insights from the three-dimensional speckle-tracking echocardiographic MAGYAR-Sport Study)
}

\author{
Attila Nemes ${ }^{\mathrm{a}, *}$, Anita Kalapos a ${ }^{\mathrm{a}}$, Péter Domsik ${ }^{\mathrm{a}}$, Mónika Oszlánczi ${ }^{\mathrm{a}}$, Csaba Lengyel $^{\mathrm{b}}$, Andrea Orosz $^{\mathrm{c}}$, \\ László Török ${ }^{\mathrm{d}}$, László Balogh ${ }^{\mathrm{e}}$, Tamás Forster ${ }^{\mathrm{a}}$ \\ a 2nd Department of Medicine and Cardiology Centre, Medical Faculty, Albert Szent-Györgyi Clinical Centre, University of Szeged, Szeged, Hungary \\ b 1 st Department of Medicine, Medical Faculty, Albert Szent-Györgyi Clinical Centre, University of Szeged, Szeged, Hungary \\ c Department of Pharmacology and Pharmacotherapy, Medical Faculty, Albert Szent-Györgyi Clinical Centre, University of Szeged, Szeged, Hungary \\ d Department of Sports Medicine, Medical Faculty, Albert Szent-Györgyi Clinical Centre, University of Szeged, Szeged, Hungary \\ e Intitute of Physical Education and Sports Science, Gyula Juhász Faculty of Education, University of Szeged, Szeged, Hungary
}

\section{A R T I C L E I N F O}

\section{Article history:}

Received 19 May 2016

Accepted 22 June 2016

Available online 23 June 2016

\section{Keywords:}

Three-dimensional

Speckle-tracking

Echocardiography

Strain

Sport

Left ventricular (LV) strains are quantitative features of LV contractility which could be easily assessed by three-dimensional (3D) speckle-tracking echocardiography (3DSTE) [1]. Evaluating elite sport activity on LV contractility is an emerging topic in recent cardiovascular research. However, results regarding to its effects on LV myocardial function are contraversial and need further investigations. The present study aimed to assess 3DSTE-derived uni- and multidirectional strains in elite highly trained athletes and to compare their results to ageand gender-matched non-trained healthy controls.

The present study comprised 20 young elite basketball and waterpolo players and runner athletes (mean age: $25.7 \pm 8.6$ years, 3 men). The mean previous years of training proved to be $13 \pm 8$ years. Their results were compared to 24 healthy controls (mean age: $22.9 \pm 2.9$ years, 9 men). None of sportmen and healthy controls has known diseases or other factors which could affect results. All sportmen and healthy controls have undergone complete two-dimensional (2D) Doppler echocardiographic examination extended with 3DSTE. Elite

\footnotetext{
* Corresponding author at: 2nd Department of Medicine and Cardiology Center, Medical Faculty, Albert Szent-Györgyi Clinical Center, University of Szeged, Semmelweis street 8, H-6725 Szeged, P.O. Box 427, Hungary.

E-mail address: nemes.attila@med.u-szeged.hu (A. Nemes).
}

athletes were selected into the Motion Analysis of the heart and Great vessels bY three-dimensionAl speckle-tRacking echocardiography in Sportmen (MAGYAR-Sport) Study among others with the aim of evaluating (patho)physiologic consequences of sport activity on LV deformations ('magyar' means 'Hungarian' in Hungarian language) [2]. Local institutional ethics committee of the University of Szeged reviewed and approved the study which conformed to the principles outlined in the Declaration of Helsinki.

Standard 2D-Doppler echocardiographic study with 3DSTE has been performed in all sportmen and matched-healthy controls with a commercially available echocardiography system (Toshiba Artida ${ }^{\mathrm{TM}}$, Toshiba Medical Systems, Tokyo, Japan) using a 1-5 MHz PST-30SBP phasedarray transducer [3]. 3DSTE imaging was performed from an apical position when six wedge-shaped subvolumes were acquired within a single breath-hold in all cases using a 1-4 MHz matrix-array PST-25SX transducer with 3DSTE capability. Chamber quantifications were performed using 3D Wall Motion Tracking software version 2.7 (Toshiba Medical Systems, Tokyo, Japan). 3D echocardiographic datasets were displayed in different views including apical two- (AP2CH) and fourchamber (AP4CH) views and different LV short-axis (basal, midventricular and apical) views (Fig. 1). These views were automatically selected at end-diastole by the software. During assessments LV endocardial border was traced by setting several reference points at the edges of the mitral valve and at the apex on $\mathrm{AP} 2 \mathrm{CH}$ and $\mathrm{AP} 4 \mathrm{CH}$ views. Later, LV endocardial surface was tracked and automatically reconstructed through the heart cycle. Over unidirectional strains including radial (RS), longitudinal (LS), circumferential (CS) strains, multidirectional strains [area tracking/strain (AS) and 3D (3DS)] were calculated using time-strain curves generated automatically by the software.

Clinical characteristics, 2D echocardiographic and 3DSTE data of sportmen and healthy subjects were compared (Tables 1 and 2). No significant differences could be demonstrated in standard 2D echocardiographic data, while 3DSTE-derived LV-CS and LV-AS were found to be significantly increased in sportmen as compared to matched healthy controls.

To the best of authors' knowledge this is the first time to demonstrate supranormal 3DSTE-derived deformational variables in elite 


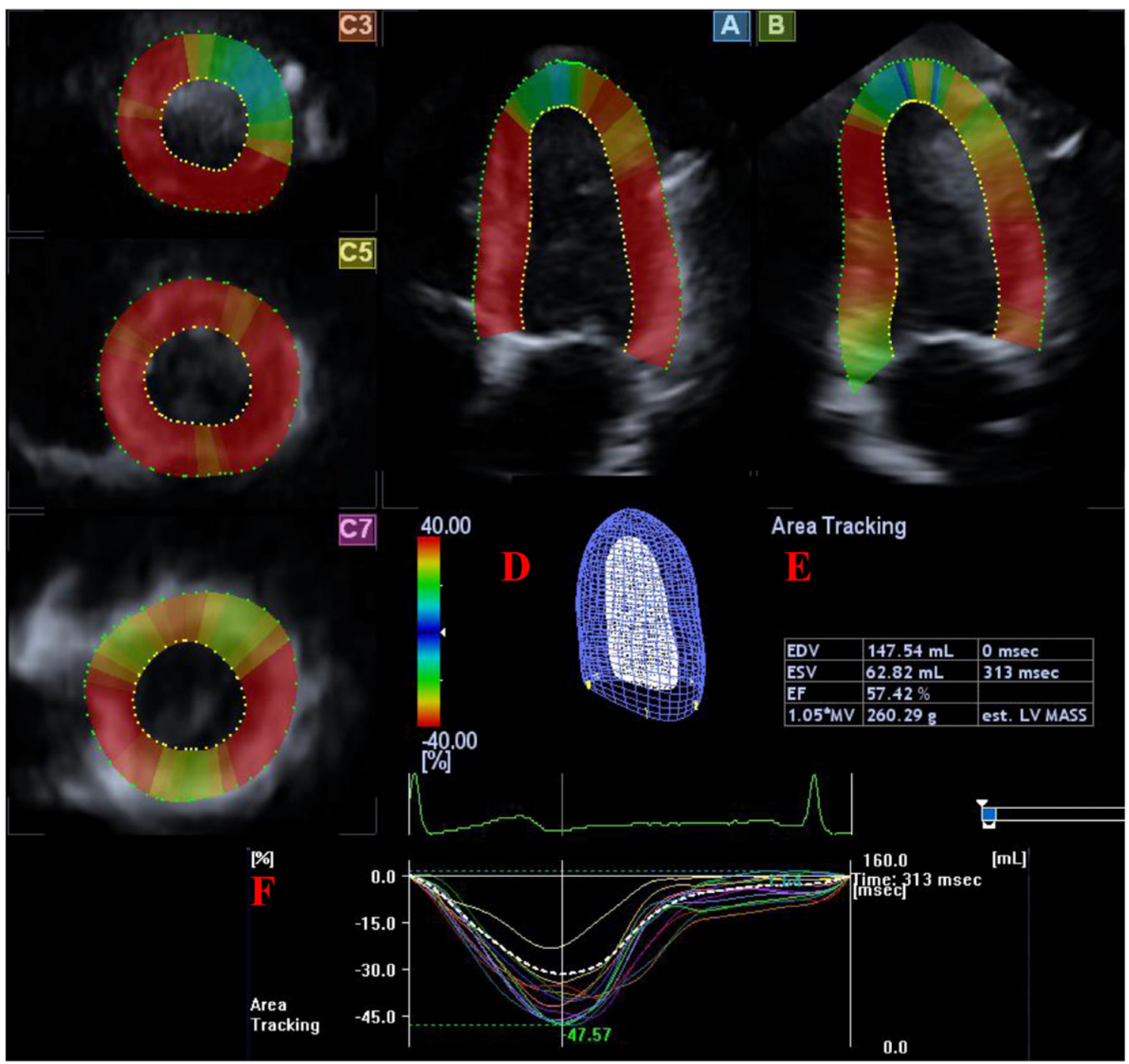

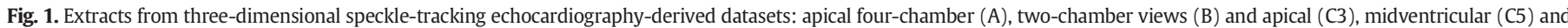

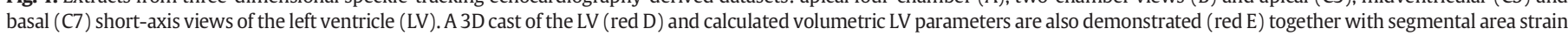
curves (red F) in a sportmen. Abbreviations: EDV $=$ LV end-diastolic volume, ESV $=$ LV end-systolic volume, $\mathrm{EF}=\mathrm{LV}$ ejection fraction, est. MASS $=$ estimated LV mass.

sportmen. One of the main benefits of 3DSTE that over LV volumetric assessments uni- and multidirectional strains could be measured at the same time using the same acquired 3D dataset. This sort of evaluation

Table 1

Clinical characteristics and two-dimensional echocardiographic data of elite athletes and controls.

\begin{tabular}{llll}
\hline & $\begin{array}{l}\text { Elite athletes } \\
(\mathrm{n}=20)\end{array}$ & $\begin{array}{l}\text { Controls } \\
(\mathrm{n}=24)\end{array}$ & p value \\
\hline Systolic blood pressure $(\mathrm{mmHg})$ & $116.1 \pm 8.2$ & $120.0 \pm 2.9$ & 0.04 \\
Diastolic blood pressure $(\mathrm{mmHg})$ & $75.5 \pm 6.1$ & $79.6 \pm 2.0$ & 0.003 \\
Resting pulse $(1 / \mathrm{s})$ & $63.7 \pm 7.5$ & $68.3 \pm 10.0$ & 0.10 \\
Weight $(\mathrm{kg})$ & $67.4 \pm 12.5$ & $70.8 \pm 19.7$ & 0.50 \\
Height $(\mathrm{m})$ & $173.1 \pm 6.9$ & $175.6 \pm 13.5$ & 0.66 \\
Body surface area $\left(\mathrm{m}^{2}\right)$ & $1.84 \pm 0.19$ & $1.89 \pm 0.32$ & 0.54 \\
Body mass index $\left(\mathrm{kg} / \mathrm{m}^{2}\right)$ & $22.4 \pm 2.9$ & $22.9 \pm 3.3$ & 0.80 \\
Left atrial diameter $(\mathrm{mm})$ & $35.3 \pm 4.5$ & $32.6 \pm 4.2$ & 0.10 \\
LV end-diastolic diameter $(\mathrm{mm})$ & $47.5 \pm 4.6$ & $48.2 \pm 4.5$ & 0.62 \\
LV end-diastolic volume $(\mathrm{ml})$ & $106.2 \pm 23.2$ & $109.6 \pm 23.5$ & 0.63 \\
LV end-systolic diameter $(\mathrm{mm})$ & $28.1 \pm 3.3$ & $27.8 \pm 4.1$ & 0.80 \\
LV end-systolic volume $(\mathrm{ml})$ & $30.5 \pm 8.1$ & $30.0 \pm 11.1$ & 0.88 \\
Interventricular septum $(\mathrm{mm})$ & $8.47 \pm 1.47$ & $7.81 \pm 2.38$ & 0.29 \\
LV posterior wall $(\mathrm{mm})$ & $9.27 \pm 1.59$ & $8.31 \pm 2.20$ & 0.11 \\
LV ejection fraction $(\%)$ & $71.7 \pm 5.6$ & $73.1 \pm 5.4$ & 0.41 \\
E/A ratio & $1.65 \pm 0.45$ & $1.68 \pm 0.37$ & 0.79
\end{tabular}

allows detailed assessment of elite sport activity-related LV deformational features. Our results confirmed increased LV-CS (and LV-AS) in elite sportmen suggesting supranormal LV contractility in circumferential direction. However, the results regarding to the effect of elite sport activity on LV function are contraversial. In a recent study with 2D strain analysis increased resting longitudinal systolic and diastolic strain and

Table 2

Three-dimensional speckle tracking echocardiographic data of elite athletes and controls.

\begin{tabular}{llll}
\hline & $\begin{array}{l}\text { Elite athletes } \\
(\mathrm{n}=20)\end{array}$ & $\begin{array}{l}\text { Controls } \\
(\mathrm{n}=24)\end{array}$ & p value \\
\hline Global left ventricular strain parameters & & \\
Radial strain (\%) & $23.2 \pm 11.1$ & $23.7 \pm 8.0$ & 0.86 \\
Circumferential strain (\%) & $-30.7 \pm 4.0$ & $-26.3 \pm 4.0$ & 0.0003 \\
Longitudinal strain (\%) & $-17.0 \pm 1.8$ & $-16.2 \pm 2.0$ & 0.35 \\
Area strain (\%) & $-43.6 \pm 3.5$ & $-38.9 \pm 4.0$ & 0.0001 \\
3D strain (\%) & $24.8 \pm 12.2$ & $25.9 \pm 7.8$ & 0.31 \\
Mean segmental left ventricular strain parameters & & \\
Radial strain (\%) & $24.9 \pm 12.0$ & $26.1 \pm 7.6$ & 0.47 \\
Circumferential strain (\%) & $-31.4 \pm 3.8$ & $-27.1 \pm 3.8$ & 0.0001 \\
Longitudinal strain (\%) & $-17.9 \pm 1.6$ & $-16.9 \pm 1.9$ & 0.09 \\
Area strain (\%) & $-44.2 \pm 3.4$ & $-39.7 \pm 11.0$ & 0.0001 \\
3D strain (\%) & $27.9 \pm 11.2$ & $27.8 \pm 18.4$ & 0.39 \\
\hline
\end{tabular}


strain rate parameters were found in experienced endurance athletes compared to the published normal values suggesting supranormal contractility [4]. In another study runners and bodybuilders were compared showing different pattern of LV deformation parameters: global LS was found to be decreased in runners, while global CS was reduced in bodybuilders with preserved global RS in both groups [5]. Our findings give further insight into the (patho)physiology of elite sport activity on LV contractility using 3DSTE, which allows real 3D analysis of LV deformation, but further population-based studies are warranted.

\section{Conflict of interest}

No potential conflict of interest.

\section{Acknowledgment}

The authors of this manuscript certify that they comply with the Principles of Ethical Publishing in the International Journal of Cardiology.

\section{References}

[1] A. Nemes, A. Kalapos, P. Domsik, T. Forster, Three-dimensional speckle-tracking echocardiography - a further step in non-invasive three-dimensional cardiac imaging, Orv. Hetil. 153 (2012) 1570-1577.

[2] A. Nemes, P. Domsik, A. Kalapos, A. Orosz, M. Oszlánczi, L. Török, et al. Volumetric and functional assessment of the left atrium in young competitive athletes without left ventricular hypertrophy. Insights from the three-dimensional speckle-tracking echocardiographic MAGYAR-Sport Study. J. Sports Med. Phys. Fitness (in press)

[3] K.A. Ammar, T.E. Paterick, B.K. Khanderia, M.F. Jan, C. Kramer, M.M. Umland, et al. Myocardial mechanics: understanding and applying three-dimensional speckle tracking echocardiography in clinical practice, Echocardiography 29 (2012) 861-872.

[4] S. Schattke, Y. Xing, J. Lock, L. Brechtel, S. Schroeckh, S. Spethmann, et al., Increased longitudinal contractility and diastolic function at rest in well-trained amateur Marathon runners: a speckle tracking echocardiography study. Cardiovasc. Ultrasound. 12 (2014) 11.

[5] I. Szauder, A. Kovács, G. Pavlik, Comparison of left ventricular mechanics in runners versus bodybuilders using speckle tracking echocardiography, Cardiovasc. Ultrasound 13 (2015) 7 . 